Harold C. Conklin: Atlas of Multispecies Relations in Ifugao

Jon Henrik Ziegler Remme

Department of Social Anthropology

University of Oslo

PO Box 1090 Blindern

0317 Oslo

Norway

Email: j.h.remme@ sai.uio.no

Phone: +4791155660

Word count: 9736 


\begin{abstract}
In his Ethnographic Atlas of Ifugao, Harold C. Conklin describes in detail the agricultural practices that have shaped a landscape of extensive terraced irrigation. While the book easily lends itself to an anthropocentric story of human control of plants and animals, I demonstrate that the book also describes how humans, plants, animals and ancestors are entangled through relations of mutual responsiveness. By drawing on concepts such as 'sympoeisis', 'becoming-with' (Haraway 2008, 2016), 'dwelling' (Ingold 2000) and my own fieldwork in Ifugao, I uncover the Atlas's hidden story of the terraced landscape as an ongoing materialization of multispecies mutuality. I argue that it is in Conklin's focus on seasons and the coordination of multispecies temporalities that multispecies relations become most visible, and I show how recent developments in the region, such as government promoted introduction of high-yielding rice and Pentecostalism have led to interruptions in these carefully coordinated temporalities.
\end{abstract}

\title{
Keywords
}

temporality, multispecies anthropology, domestication, becoming-with, the Philippines 


\section{Harold C. Conklin: Atlas of Multispecies Relations in Ifugao}

\section{Introduction}

For being a purportedly human-oriented science, anthropology has been conspicuously replete with plants and animals. The protagonists in the stories told through anthropology's history might well have been humans, but nonhuman characters certainly make their appearances as well. Some of these have become almost like emblems of the discipline (Smith 1972: 391). After all, what would anthropology have looked like without Trobriand yams, Nuer cattle, Bororo parrots, Balinese cocks or globalised sugar canes (Malinowski 1935; Evans-Pritchard 1969; Levi-Strauss 1969; Geertz 1973; Mintz 1986)? Nevertheless, animals and plants have to a large extent been reduced to cameo appearances - as good to think and good to eat - in what appears as an otherwise rather anthropocentric story of control, domination and exploitation of nonhuman others (Lien, Ween, and Swanson 2018). Current anthropological theorising, however, particularly that part of it associated with multispecies anthropology (Kirksey and Helmreich 2010; Kirksey 2014) and various shades of more-than-human scholarship (Haraway 2008, 2016; Tsing 2015; Cadena 2015; Lien 2015; Kohn 2013), has shuffled, and perhaps also deliberately muddled, the dramatis personae of anthropological storytelling. Transformed through the well-known narrative technique of revealing false protagonists, anthropology's humans now share the stage with a flourishing multitude of critters that are diverse and mutually entangled with each other and with humans in ways that range from love to cruelty and everything in between. Along with a 
concomitant redefinition of 'human nature as an interspecies relationship' (Tsing 2012: 144) and a realisation of human impact on biological, hydrological, geological and atmospheric systems known as the Anthropocene, the differentiations and forms of relations between humans, plants and animals in anthropological storytelling have in many ways become destabilised.

The new stories we tell about humans and their companion species (Haraway 2008) thus transform the characters that former stories of human control and domination over plants and animals depend on. As we know, going cold turkey can be a rather unsettling experience. But it can also be rewarding. For these new ways of relating may not necessarily undermine former stories. Indeed, similar plots might actually hide in different forms of storytelling. Maybe today's multispecies anthropology has more in common with previous approaches to human-nonhuman relations than we think?

We are fortunate in that our former colleagues often did a tremendous job documenting, often in meticulous detail, human practices with nonhuman others. The ethnographic, or should we perhaps say eco-graphic, richness of these accounts often by far exceeds what was necessary for making their theoretical points. The excess of these accounts invites us to reread them in ways that carve different paths through their dense well-described eco-graphic jungle. It is an excess that offers a rereading that is at once critical and generous and one that allows us to see otherwise the human-nonhuman relations they describe.

In one of these former accounts, Harold C. Conklin's Ethnographic Atlas of Ifugao: A Study of Environment, Culture, and Society in Northern Luzon (1980), we read about the ways in which farmers in the Philippine highland province of Ifugao construct and maintain their extensive system of irrigated terraces, how they go about 
to cultivate wet rice in them and how they grow vegetables, sweet potatoes, legumes and tubers in swidden gardens. Following their practices with plants and animals throughout the seasons, Conklin's Atlas seemingly tells a story about human land use, their domestication of plants, and their continuous efforts at controlling natural forces and engineering the landscape around them. The book thus easily lends itself to a reading that supports an anthropocentric story of human control, domination and exploitation of plants, animals and other natural forces.

However, I argue in this article that Conklin's ethnoecological focus actually betrays this anthropocentric story and rather opens up for a quite different reading of the terraced landscape, one that is actually quite contiguous with contemporary multispecies perspectives. This is a reading that foregrounds the variety of ways in which relations of mutual responsiveness entangle humans, plants, animals and a host of other nonhuman beings in specific ways, and one that sees this admittedly impressive landscape as the historical and continuous materialisation of these relations. I draw on concepts such as 'sympoeisis', 'becoming-with' (Haraway 2008), 'and 'dwelling' (Ingold 2000) as well as my own fieldwork in the $\operatorname{area}^{1}$ to re-read Conklin's Atlas in order to elicit the concerns with more-than-human sociality and multispecies responsiveness that Conklin seems to have had but which he, for various reasons, left implicit, teeming between the lines, but often sidelined by concerns with classification, measurement and enumeration.

In the second part of this article, I argue that Conklin's understanding of multispecies entanglements become particularly visible through his attention to the

\footnotetext{
${ }^{1}$ I conducted fieldwork in and around the municipality of Banaue, Ifugao in 2003-
} 2004 and 2007-2008. 
careful but also uncertain coordination of plant, animal, human and spirit temporalities that together make up the area's seasonal rhythms. Furthermore, I show how the government led introduction of new varieties of rice and snails and the conversion to Protestant Christianity challenge these carefully forged coordinations. I begin, however, with a discussion of Conklin's ethnographic style and show how the apparent lack of theorisation in his work can be understood as related to his often overseen politically engaged commitment to demonstrating the ecological soundness of indigenous agricultural practices.

\section{The Politics of Fine Description}

The jagged Cordillera Mountains of northern Luzon, the Philippines with their sharp mountain ridges and steep drops, clad with dense jungle, are an impressive sight. What is even more impressive are the ubiquitous terraces that cover entire mountainsides and at places almost drown the small hamlets of stilt-built wooden houses that lie interspersed between them. Supported somewhere by up to twenty meter high stone walls, terraces follow upon terraces from deep down river ravines to higher mountain ridges several hundred meters above. Water trickles through them, by a maze of small creeks, larger streams, somewhere redirected through bamboo tubes and on to, of course, the terraces themselves, flooding them and seeping down to those below. Allegedly carved out by current inhabitants' ancestors and mythical forebears, this is a landscape infused with history. It is a living memory of the past, and at those places where terraces, now increasingly, lie dry and barren, a reminder of what the future might bring ${ }^{2}$.

\footnotetext{
${ }^{2}$ Earlier scholars (e.g. Beyer 1955) proposed that the Ifugao terraces were 2000-3000 years old, while more recent historical and archaeological studies claim a more recent
} 
This landscape has fascinated people for centuries. Early Spanish colonial explorers were clearly impressed with the engineering skills of the Ifugao. One of them described the terraces as 'a stupendous piece of work' (Willcox 1912: 152), a description that is echoed by the thousands of national and international tourists who flock to the region every year to admire what is marketed as the 'Eighth Wonder of the World' and the 'Stairways to Heaven'.

Earlier researchers such as Francis Lambrecht and Roy F. Barton used this landscape as background for their early twentieth century studies of legal, ritual and social practices in the area (e.g. Lambrecht 1932-1951; Barton 1922, 1969). But the landscape itself had not been thoroughly documented and analysed until Conklin, then a teacher at Colombia University, made his way there in the late 1950s-early $1960 \mathrm{~s}^{3}$. Having previously conducted fieldwork on Mindoro, which resulted in his Yale University PhD-thesis entitled 'The relations of Hanunóo culture to the plant world' (Conklin 1954b), and having a keen interest in ethno-biological classification and

origin of the terrace systems, seeing them as results of population expansion into the highlands as a response to Spanish colonization (Keesing 1962; Acabado 2010). ${ }^{3}$ Conklin began his anthropology studies at Berkeley in 1943 where he was taught by Robert Lowie and Albert L. Kroeber. A year later, he was sent to the Philippines as a soldier in the US Army. When his service ended, he remained in the Philippines and spent three and a half month with the Hanunóo in Mindoro. When returning to the US, he completed his undergraduate studies at Berkeley and was admitted to graduate studies at Yale. After he received his $\mathrm{PhD}$ in 1954, he held a position at Colombia University before he, in 1962, became professor at Yale University where he stayed until he passed away in 2016. 
ecology, it was perhaps no wonder he was drawn to study a region where land use patterns had taken such remarkable forms. What eventually transpired from the fieldwork he started in 1961 took a no less remarkable form. Far from a conventional ethnographic monograph, Conklin published his book as an ethnographic atlas. As the title suggests, neither is this a conventional atlas. It contains, as one would expect, a large collection of maps, some of historical origin and some resulting from cooperation with his Ifugao informants. But it also contains pictures and not least descriptions of Ifugao agricultural practices and how these are shaped by social and cultural factors. By combining a variety of methods including historical cartography, aerial photography and photogrammetry (i.e. making measurements from photographs) with more traditional anthropological methods of participant observation and formal and informal conversations with informants, Conklin attempted to elicit what he described as 'the underlying patterns and processes that have produced and maintained these extremely imageable outer forms' (Conklin 1980: 1).

Conklin's primary way of getting at these processes is through his insistence on very detailed and particular description of concrete practices. He provides therefore a comprehensive account of the entire agricultural year. He describes the long meticulous work of preparing the fields after the previous year's harvest weeding, threading decaying rice straws into the mud, removing shells and snails, cleaning and repairing terrace walls, draining the terraces, levelling the mud that they contain, refilling them with water, and cleaning drainage canals. He covers the planting of rice, the weeding during the growing season, and finally the highlight of the agricultural season, harvesting. Along the way, he refers to the rituals they perform at every one of these stages, and he describes and classifies the various 
landforms - grassland, forestland, caneland, woodlot, swiddens, house terrace, drained field and pond field - and shows their complex interrelatedness over time. He details how they construct terraces, and how they clear, burn, plant and harvest swiddens, as well as all the activities related to wet-rice cultivation in the irrigated terraces. And he does so with a remarkable sense of detail, one that attests to his capacity for 'fine description' (Frake 2007) and to his reputation as 'one of the very best fieldworkers in the business' (Geertz 2007: 28). The women who do the planting, Conklin writes,

(...) remove handfuls of seedlings (still attached in convenient batches by the original seed panicles) and place two or three stems at a time, by thumb and forefinger action, firmly into the pond-field mud (...). Transplanters step backward as they move away from the dikes and margins. Uninterrupted, a woman makes forty to fifty such implantings a minute. As the work proceeds the women usually keep several meters apart so that when they complete the meter-wide strips of transplanted surface (binītu), empty areas of about the same width are left between them, to be filled up ('imbūhu') easily (...) (1980: 22).

With its extremely detailed descriptions of which fingers they use and which way they move, this excerpt is pretty representative for the Conklin's descriptive style. The Atlas contains numerous measurements and enumerations together with ample listings of vernacular terms and classifications. We learn for instance that they refer to weeding terrace walls to remove hiding places for rodents is as 'ahilupung and that this requires 'about 30 work-day equivalents per hectare of pond-field area' (Conklin 1980: 29). 
Although in many ways highly impressive - imagine the nitty-gritty fieldwork lying behind all of this - the writing style makes reading it at times like 'bushwhacking through long thorns', as one reviewer phrased it (Hanks 1982: 207). Beyond these rather dry observations and detailed descriptions one should not expect much in terms of theorisation when reading Conklin. What is there hides well between the lines. And although people appear in the many pictures the Atlas contains, we do not get rich narratives of lived life.

Conklin's no-nonsense, almost technical, style should, however, not be taken as an indication of theoretical ignorance or non-engagement with the lives of his informants and their social and political difficulties. Conklin was fully aware of the theoretical controversies that infused anthropology at the time and his emotionally sensitive portrait of Maling, a 7-year old Hanunóo girl who lost her younger brother clearly attests his ability to write sympathetically about lived life (see also Geertz 2007; Dove 2017, 196). In the Atlas, however, he chose to write differently. As Kuipers and McDermott (2007) note, Conklin wrote for future generations and held that ethnographers had higher responsibilities than arguing with each other. Conklin's style must therefore be understood as a deliberate choice of wanting to 'recover, represent, and preserve knowledge of how the Hanunóo and Ifugao worked, talked, thought, and played' (Kuipers and McDermott 2007: 2).

But his ideas about theory and ethnography can nevertheless be glimpsed if one looks carefully. Conklin insisted on detailed particularity, which he combined with what Michael Dove has described as the art of the 'ethnographic caveat' (2007: 418) - always underlining the fact that his categorisations are tentative and incomplete. Conklin thus made a strong case against any form of essentialism. He argued already in 1954 for an ethnoecological approach that took local ecological 
knowledge seriously (Conklin 1954a) ${ }^{4}$, and in the Atlas he follows up accordingly through his extensive documentation of vernacular terms, categorisations and classifications. Moreover, by including one of his informants, Puggūwon Lupāih, and his cartographer Miklos Pinther as co-authors on the frontpage, Conklin foreshadowed the debate that would later appear regarding ethnographic authority, writing and representation.

However, Conklin also had a political agenda with his mode of presentation. Conklin wrote at a time when Hanunóo and Ifugao ways of living, especially the way they practiced swidden or slash-and-burn farming, were heavily disparaged by public opinion and governmental policy makers (see Masipiqueña, Persoon, and Snelder 2000). Documenting in technical detail how this form of agriculture works, Conklin actually made both a scientifically sound and a socially engaged case for the depth of their knowledge and the ecological robustness of their practices. He thus challenged the high-modern forms of agricultural development that the Philippine government and international development organisations promoted at the time. Conklin probably foresaw many of the distorting effects of the government's Green Revolution Program with its introduction of new varieties of high yielding rice and use of chemical fertilisers and pesticides (Rosaldo 1993: 184-185; Dove 2007; Acabado and Martin 2015).

\footnotetext{
${ }^{4}$ Along with scholars like Charles Frake (1962) and William Sturtevant (1964), Conklin promoted an ethnoecological approach that combined studies of environmental knowledge with linguistics to understand how people organize and classify their knowledge about the environment and how this is related to their practices with plants and animals.
} 


\section{Caring for Terraces}

Conklin's insistence on detailed descriptions, on paying attention to 'kinds of things and ways of doing' (Kuipers and McDermott 2007: 7) was clearly connected to his engagement in establishing ethnoscience and ethnobotany as anthropological disciplines. But the level of details in Conklin's work leaves us also with an opportunity to poach on (Kirksey, Schuetze, and Helmreich 2014: 7) and re-harvest the wealth of information it contains. For by reading carefully, one sees clearly that from out of the cracks in the technical rhetoric, behind the constant enumeration, measurements and lists of vernacular categorisations, seeps a concern with the ways in which the Ifugao respond to and are attentive towards the plants and animals and other nonhuman beings that inhabit and take part in transforming the landscape. Looking carefully helps too, because the upper half of each page holds pictures, more than 180 in total. The contrasts to the dry, enumerative descriptions become at times quite intriguing. For instance, one page lists on the lower part the vital data for an average bundle of rice (volume: $3840 \mathrm{cc}$, weight: $1497 \mathrm{~cm}$, number of panicles: 320, girth at bound neck: $10,5 \mathrm{~cm}$ and so on) and on the upper, shows a picture of a young girl squatting down and carefully putting, or rather, guiding a small chicken into a chicken coop that will be hanged up under the house roof during the night to protect it against snakes and other predators (Conklin 1980: 11) .

\footnotetext{
${ }^{5}$ The little chicken and the domestic piglets on one of the other pictures on the same page most probably had their throats cut over in a later sacrificial ritual. Taking care of chickens and pigs while they are alive, feeding them particular kinds of food, making sure they are well, is a requirement for them to become suitable sacrificial animals (Remme 2014, 2018).
} 
The care Conklin depicts in the picture of the little girl and her chicken also points to one of those cracks that reappear amidst Conklin's technical writing. For Conklin states that since natural erosion can easily and quite rapidly reduce wellmaintained terraces to a rough hillside, the terraces demand 'constant attention and structural care' (Conklin 1980: 16, my emphasis). And furthermore, the 'terraced pond fields demand meticulous care in the control and use of all forms of surface water' (Conklin 1980: 27, my emphasis). Structural and meticulous care? What did he mean by that? The care Conklin refers to here could on the one hand be read as a form of assiduous human control. The massiveness of terrace systems makes them appear quite durable. Conklin's inclusion of photographs of the same terraces from different time periods showing a remarkable consistency also contributes to that (e.g. 1980: 36). However, terraces do in fact deteriorate quite easily if they are not more or less constantly maintained and actively used for cultivation. At the start of every postharvest season, farmers must weed, repair damaged dams and dikes, cut remaining rice straws and thread them into the mud, fix stone walls and refill the top of these with the mud that later dries and hardens to form the banong, the dike holding the water inside the terrace.

Failing to perform this maintenance work leaves the terraces open to the deteriorative influence of a variety of forces. Weeding is crucial for preventing plants to grow large roots that may penetrate into and damage the stonewalls. Keeping the margins of rice terraces clean by cutting down and burning weeds is also done to keep down the rats (Conklin 1980: 20) that dig holes into the soil supporting the terrace. During heavy rain such holes may be filled with water that eventually digs its way out of the stonewalls and burst them asunder. Weeding along irrigation channels and drainage canals also inhibits this to happen as it contributes to 'an assured, constant, 
and known agricultural needed flow' and allows 'for the rapid evacuation of massive volumes of floodwater as speedily as possible' (Conklin 1980: 28).

Carefully controlling the forces that work both for and against these tasks is vital for maintaining the terrace system. 'How to plan, balance, manage, and control these transformations is the concern of every Ifugao household', Conklin concludes (1980: 37). However, one should not necessarily read this in terms of a kind of care that emphasises anthropocentric control and domination. For while the weeding, wetmulching and rice cultivation may contribute to sustaining an age-old irrigation system, the Atlas also provides ample indications that a much more heterogeneous constellation of forces is at play. Within this constellation humans do play a significant part but do so as part of a dynamic collective that includes a variety of plants, animals and other other-than-human beings.

\section{Sympoeitic Terraces}

It matters which terms we think Ifugao terraces with. At this point, I would like to draw on a distinction that Beth Dempster has made between autopoeitic systems and sympoeisis, as it has been adopted by Donna Haraway (2016). An autopoeitic system is a self-producing autonomous unit with self-defined spatial or temporal boundaries that tend to be controlled, homeostatic, and predictable. Sympoeisis, by contrast, is a term for 'collectively-producing systems that do not have self-defined spatial or temporal boundaries. Information and control are distributed among components. The systems are evolutionary and have the potential for surprising change' (Haraway 2016: 61).

Looking at the terraced landscape as an autopoeitic system would see it as composed of units or beings that may relate but which are fundamentally autonomous. The units precede their relating. The Atlas's emphasis on human engineering, how 
balancing, managing and controlling landscape transformations is the concern of every household, may be taken as an invitation to an autopoeitic reading of the terraces, one sees them as constituting a bounded system that has a controlled, homeostatic and predictable character.

However, although Conklin focuses on managing and controlling the landscape, he also emphasises the transformations that occur and shows that building and maintaining the terraces is founded upon a responsive attentiveness to the unpredictable agentive influence of plants, animals, water, stones and other forces at work. Thinking the terraced landscape described in the Atlas as a sympoeitic rather than an autopoeitic system brings out this more-than-human sociality (Tsing 2013) and the distributed responsiveness involved in its emergence, endurance and the seemingly predictable, but yet always uncertain transformation. And not only that, seeing the landscape as sympoeitic reveals, as I elaborate below - the ways in which its entities - humans, animals, plants and ancestors are far from self-defined autonomous units. Rather, their very existence is fundamentally relational. They do not precede their relations but emerge through what feminist scholar Karen Bard (2007) terms intra-action by which she means that entities materialize in and through entanglements and that their ability to act emerges from within this relationships rather than preceding it.

Sympoeisis is, as Haraway says, proper for describing such 'complex dynamic, responsive, situated, historical systems' (Haraway 2016: 58) that the Ifugao rice terrace systems are. The 'constant attention and structural care' that Conklin refers to could thus be understood to be a sympoeitic form of care, one in which humans are attentive to and responsible to the lively multispecies relationality in ways that render capable (Despret 2008) and response-able (Haraway 2008: 71) all kinds of 
animate forces. Sympoeisis means 'making-with' (Haraway 2016: 58) and is a quite succinct way of describing the constellation of forces and entities involved in the emergence, maintenance and transformation of the terraced landscape.

Conklin's grasp of the multispecies quality of the landscape comes to the fore in various ways. One of them is that he insists on referring to the terraced fields not as rice terraces but as pond fields. A seemingly innocent difference, but as his students have reported (Kuipers and McDermott 2007; Anderson 2007), Conklin took terms very seriously. As the Atlas clearly shows, these fields harbour much more than rice, and this assemblage of life forms is vital for their productivity. Weeds are cut and submerged in the mud, and the muddy water itself teems with snails, clams, shells, snails and mudfish. 'These forms of life keep the water and muddy soil in pond fields active and, as Ifugao farmers say, 'fertilised" (Conklin 1980: 14). Conklin notes that there is a strong emphasis on the rice farming aspect of these fields, but by consistently referring to them as pond fields, he underlines their lively multispecies character ${ }^{6}$.

\section{Ancestral Collaborators}

Part of this making-with is done by beings who are not easily spotted, neither in the Atlas nor the real world of present day Ifugao. These are the beings that Conklin refers to as 'ancestors, local spirits, and hundreds of gods (1980: 12) but which we

\footnotetext{
${ }^{6}$ Conklin's multispecies perspective on pond fields is thus aligned with recent retheorizations of domestication that sees domestication not as a singular relation between humans and a particular plant or animal species but rather as characterized by open-ended, multispecies and potentially transformative ecological relations (Lien, Ween, and Swanson 2018; Swanson 2018; Remme 2018).
} 
might as well think of as the cohabitants of this landscape along with humans and other living beings. In the Atlas, these beings are not major characters. Conklin alludes only briefly to their significance by mentioning the sacrificial rites performed at various stages of terrace preparation, planting and harvesting. For instance, a new agricultural year begins after harvesting and before the first season begins, an initial agricultural rite called $l u$ 'at is performed in each landowner's house in which chickens and pigs are sacrificed (Conklin 1980: 14). Farmers perform similar rites throughout the agricultural year. Of the 37 types of rituals Conklin identified, 17 of them were linked with rice production and consumption. But apart from describing the timing of the rituals, providing their local terms and specifying the kinds and number of sacrificial animals, Conklin gives us little to work with to understand the nature of the relationships between them, living humans and other critters.

Nevertheless, read in the light of previous and recent (Barton 1946; Lambrecht 1932-1951; Remme 2016) accounts of Ifugao rituals and the character of humannonhuman relations, Conklin's description of the attention and care involved in Ifugao agriculture shows how maintaining terraces, cultivating rice and gardening in swiddens involve tuning into and responding to the wills and preferences of these beings.

For the terraced landscape is not only home to those humans who inhabit the clusters of houses - some made of concrete and corrugated iron, others of the more traditional stilt-built wooden type - that lay spread around in the terraces or on top of mountain ridges. In creeks, large stones, thickets and other places live place-specific pinādeng spirits, and ancestors and hundreds of other forms of other-than-human beings, although usually in a way imperceptible to humans. These beings share with humans the capacity to harbour a life force, lennāwa, which also gives them a certain 
sense of consciousness and subjectivity. Lennāwa is necessary for bodies to become alive, although it can leave the body temporarily, as in dreaming for instance when the lennāwa leaves the body and operates on its own. This is so not only for human bodies. Spirits, animals, and plants too have lennāwa and need to do so in order to live and reproduce. For rice to grow and yields to magnify, lennāwa must flow into the fields, something that occurs only if relations between humans, ancestors and other spirits are properly enacted. Spirits may interfere in the flow of lennāwa and thus cause damage to the harvest, and only by performing rituals in which spirits are given chicken and pigs - or the lennāwa of these sacrificial animals to be specific can such damages be repaired and prevented. Initiating the agricultural year through performing the lu'at ritual and follow up with similar rituals at important phases of the agricultural cycle is one way to ensure this flow. Failing to perform such rituals would entail showing disrespect towards the ancestors and spirits, something that could not only result in poor harvests, but also and even more devastating, in landslides and ruination of terrace lands.

The inter-subjective character of wet-rice cultivation in Ifugao challenges a view of this as 'agricultural production'. As argued by Descola, in Western thought the idea of production rests upon two interdependent premises: that an individualised intentional agent is the cause of the coming-to-be of beings and things and that there is a radical difference between the ontological status of the creator and the object created (2013: 323; Sahlins 2017). These premises guide conventional narratives of human civilisation and domestication. The very idea of the 'Neolithic revolution' for instance, operates upon a conceptualization of humans as subject creators becoming 
emancipated from the environment through their agential actions with environmental objects (Childe 1928: 2) ${ }^{7}$.

Ifugao terrace construction and the cultivation going on in them hardly fit with any of these premises, and it is therefore misleading to see their coming into existence as the result of a human controlled mode of production. Instead, what is at work here is rather to be understood as a continuous process of multispecies sympoeisis.

Myths narrated at rituals and other festive occasions relate how 'people of the olden times' carved out and built the very terraces that are in use today. The sympoeitic character of this work is particularly evident in how the myths blur the distinctions between humans, animals, spirits and mythical figures who are all included in a sociality that extends to include all kinds of persons (Remme 2017b). The terraced landscape thus holds memories of these ancestral forms of sympoeisis. The blurredness is of crucial importance here, for it is from out of this that the differentiations between different kinds of beings emerge and become actualised (Viveiros de Castro 2007; Remme 2016).

But such blurredness belongs not only in the mythical past. All beings having lennāwa have a potential for metamorphosis. A human may easily turn into an ancestor, and a bird may reveal itself to actually be a spirit. This metamorphic potential can be exploited, for instance by ritual experts who do so during possession, but can also be dangerous. Becoming human and remaining so requires relating with others - humans and nonhumans - in specific ways, although the result remains

\footnotetext{
${ }^{7}$ The idea that human civilization emerged with our ability to transform our environment through labour was also foundational for Marxist social theory, which was also a major inspiration for Childe's work (see Lien, Ween, and Swanson 2018).
} 
volatile, uncertain and to a certain extent unpredictable. The sympoeisis at work here is therefore not an interaction between beings, but an intra-action of becoming-with (Haraway 2016: 125; Barad 2007: 141), both as an on-going relational process and as an ancestral legacy.

Looking at the terraces today, my informants would often express their acknowledgement of this ancestral legacy. Past intra-actions are inscribed in the landscape and working with this landscape involves a working-with these, both in terms of their material remains and - as the frequent rituals indicate - in terms of engaging in new intra-actions with other co-present sympoeitic collaborators (Haraway 2016: 102).

These perspectives invite reading Conklin's claims that 'social groupings, customary activities, and land forms are intricately interrelated' (1980: 4) in a different light than one that emphasises the anthropocentric control of the transformation of land forms. Social groups are wider and more inclusive, and the interrelatedness of these elements is of a kind in which they do not relate as independent entities that engage in relations with each other, but one through which a multiplicity of entities emerge through intra-action.

Is the Atlas, then, really a description of 'land use' (Conklin 1980: 2) and 'land and society' (Conklin 1980: 4)? And what does it really mean that '(e)verywhere, local economic activities are directly related to the agricultural and ecologically attuned management of fields'(Conklin 1980: 1, my emphasis). Ingold draws a contrast between land and nature as quantitative, homogeneous and separate from humans on the one side and landscape as qualitative, heterogeneous and relational on the other. The former implies what Ingold terms a 'building perspective' on landscape as a neutral backdrop to human activities or as a product of human 
ordering of space. The latter - the 'dwelling perspective' - sees landscape rather as 'generated and sustained in and through the processual unfolding of a total field of relations' (Ingold 2000: 156), a field of relations that includes both human and nonhuman components and that stretches back in time to include ancestral forms of such heterogeneous assemblages. When Conklin describes 'land use' by detailing terrace construction, expansion and repair, his dry technical prose may mislead us into taking this as an account of a 'building perspective'. But there is subtext here of a more ecologically attuned sensibility that suggests a reading more in line with Ingold's dwelling perspective. Contrary to seeing the form of this landscape as the result of the building efforts of great engineers, such a sensibility sees the landscape as the result of an on-going ecologically attuned management of fields.

\section{Multispecies Temporalities}

In an interesting twist, the spatial focus of the book - the Atlas-format, the large collection of maps and the attention to classification of land forms and their interconnected transformations (Conklin 1980: 7-9) - is complimented by an emphasis on the temporal dimensions of Ifugao agriculture. The Atlas can in fact be seen as organised around the temporality of the terraced landscape. The book's main section, which is called The Agricultural Year, is as a sequential description of the agricultural year, taking us through all the different phases of wet-rice cultivation. This temporal structuring of the book is supplemented by other temporalising techniques as for instance juxtaposing photographs taken in 1945 and 1963 of the same terrace areas (Conklin 1980: 36) and by providing a more long dureé perspective on landscape transformation through historical cartography from the area.

The Atlas's temporal focus does not only provide an account of the sequential ordering of the agricultural year, however. It is in writing about temporality that 
Conklin's potential dwelling perspective most clearly pushes through the long thorns of technical 'building' rhetoric. As I show below, it is through the temporal complexities that Conklin reveals his nuanced and dynamic understanding of the distribution of agency beyond humans to plants, animals and nonhuman others.

That it is through a focus on temporality that this perspective becomes most visible may not be that surprising. As Greenhouse (1996) has argued, how people conceptualise time articulates people's understandings of agency. Paying attention to the practices through which humans time their actions, how they adapt their practices in relations to the rhythms and temporalities of other entities, for instance plants, might 'render perceptible the relations through which plants' capacities to become affected and to affect - their agencies - come to move humans' (Brice 2014: 947). Conklin warns already from the start that in order to keep track of agricultural events, some knowledge of 'the local system of time reckoning' (Conklin 1980: 13) is required. The agricultural year is divided into two phases: a field preparation phase and a grain production phase. These phases are subdivided into a total of four seasons; the terrace formation season ( 'iwang), the planting season (lawang), the dry season (tiyalgo) and the harvest season ('ahitulu). These four seasons are further subdivided into fifteen periods, and the totality of these divisions is again correlated with twentytwo stages of agricultural activity and twenty-three associated rituals.

The exact timing of the seasons is hard to predict as external systems of dating, such as the Gregorian calendar, is not much used, Conklin states. Instead, the system depends on the recognition of a succession of observable environmental changes and of agricultural activities related to terrace maintenance and rice cultivation (Conklin 1980: 13). Already at this point, Conklin acknowledges the heterogeneous character of Ifugao agricultural temporality in two different ways. 
First, temporality is heterogeneous in the sense that time periods - the agricultural year, seasons, and other subdivisions of these - are in effect assemblages of a multiplicity of human and nonhuman temporalities. The rhythms of the agricultural year come about through the dynamic but also uncertain coordination of human and nonhuman temporalities (Krause 2013; Harris 1998).

Conklin emphasises the role of rituals in marking the transition from one season to another. Human activity thus plays an important role in the temporality of rice cultivation. However, this should not be taken as evidence of human control over agricultural seasonality. Far from it, the termination of one season or period and the commencement of another come about through what Conklin describes as an 'intercalibration of various phenological fluctuations and local cultural activities' (Conklin 1980: 13).

This intercalibration rests on a careful attention to the rhythms and temporalities of plants, animals and ancestors and spirits. These include the growth of plants, variations in meteorological phenomena, the changes in insect and rat damages, and the signs given by ancestors through rituals. Together all these different transformations become 'time-givers' (Adam 1990) which affect how humans act and how landscape is transformed. A crucial role here is played by the tomona', the agricultural leader of a certain agricultural district.

An agricultural area is divided into distinct districts, himpuntona 'an, that are characterised by a shared water source. Each of these districts has one particular ritual field, puntona'an, in which rituals for the district are performed. The owner of this ritual field is called a tomona' serves as the district agricultural leader.

It is the tomona' who decides, for instance, when they shall begin transplanting seedlings from seedbeds into terraces, that is when the 'ahiboge, the 
seedling transplanting period, shall begin. The tomona' follows closely the maturity of seedlings, the warming temperature and the diminishing of cloud coverage and eventually performs a ritual to consult the ancestors and spirits. Given the auspicious and successful completion of the ritual, the transplanting of seedlings begins at the district's ritual-field. After a day of ceremonial rest, the owners will transplant in the rest of the district's fields. This synchronisation is vital for the harvest to succeed as it compresses the later harvesting phase into a very short period, thus inhibiting a prolonged period when mature rice is at risk of attacks from insects and birds.

Similarly, throughout the agricultural year, changes between seasons and periods occur through a heterogeneous attuning to a variety of rhythms and temporalities. The exact distribution of causal forces affecting the year's progress is not fixed (Remme 2014a), and the strength of influence that the various components that take part in this assemblage of temporalitites have, differ throughout the year. While certain transitions may rest heavily on the maturation of rice panicles, another transition is guided more by will the ancestors, although in all cases the variety of components are consulted as well.

The second way in which the Atlas evidences a heterogeneous temporality is through the co-existence temporalities that occurs in different parts of the landscape because 'districts differ in their ecological settings and because owners of ritual fields have some leeway in initiating agronomic activities' (Conklin 1980: 13). While seasons broadly follow the same sequential pattern in all districts, there is considerable variety within a single agricultural area. In one district, the rhythms of plants, animals, humans and spirits may together affect the transition into lawang, planting season, while in a district located higher up in the mountains, for instance, 
may follow a rather different rhythm. The result is a multiplicity of agricultural temporalities.

A further complexity in this multiplicity is added when Conklin emphasizes that the temporality of the irrigated terraces are further entangled with two additional agricultural areas, namely the swiddens and the woodlots.

While it was common to see extensive agricultural such as swiddens as evolutionary prior to more intensive forms like irrigation, Conklin showed that these different agricultural methods often were concurrent and formed part of a carefully managed agricultural complex (Acabado 2012; Remme 2018; Dove 1983). The exact relations between these three areas has been a matter of some dispute, where Conklin saw the irrigated terraces as determinant within the agricultural system and swiddens more as insurance against failed wet-rice harvests while others claimed that irrigated terraces were made only to the extent that the limits of swidden cultivation necessitated it (Dove 1983: 518).

That these three agricultural areas are in any case closely connected is evident when Conklin describes them, in what I suspect is an accidental but nevertheless intriguing Deleuzian vocabulary, as a complex interlocking of agricultural cycles that 'have different durations and exhibit varying intensities with respect to demands for natural resources and labor' (Conklin 1980: 36, my emphasis). As a result, the temporality of Ifugao landscape is in this way a heterogeneous temporal multiplicity in which various durations are intercalibrated to resonate rhythmically with each other.

In sum, the agricultural year consists of an interlocking of rhythms and cycles in which, as Elaine Gan describes it, 'human activities and feasts are incorporated into the cycle of rice growth in terraced pond fields, which are incorporated into the 
patterns of multiple land forms and longer cycles of shifting cultivation, which are further incorporated into astronomical and lunar cycles' (2016: 146).

\section{Rhythmic Interruptions}

The connections between the landscape's heterogeneous temporalities and the distribution of agency to plants, animals, ancestors and spirits are carefully coordinated but are also inherently volatile. They have their own internal instability, but the rhythmic coordinations also face other forms of interruptive forces such as the conversion to Pentecostalism and government-led attempts at developing rice cultivation.

Although ancestors and spirits remain important collaborators with many in Ifugao, a slowly increasing number of people have converted to various Pentecostal congregations. Members of these are for the most part opposed to ritual practices related to ancestors and have 'demonised' the spirits. Not becoming affected by these demonic forces is a major occupation of converts and this can take different forms like praying, attending church, and performing delivery rituals. But it is also done in more mundane ways such as refusing to follow the planting rhythms led by the tomona'. Seeing the tomona',s relation to ancestors and spirits as evidence of his demonic influence, negating his decrees on when to plant and harvest thus becomes a deliberate attempt at either avoiding the influence of demons or at denying the attribution of agency to ancestors and spirits altogether (Keane 2007).

Conversion involves also a temporal transformation, changing in many ways the punctuation of time, in terms of the weekly worship schedule, the life cycle and through focusing on the relation between the present and the soon-to-come End Time. Accompanying this is also a redefinition of spirit and ancestor related practices as belonging to what my Pentecostal informants referred to as 'a pagan past'. 
The temporality of Ifugao landscape is thus not only an ecological time (Evans-Pritchard 1969), in which sensitivity to environmental changes are fundamental for time-reckoning. That ecological time is entangled in a wider temporal ecology where different reckonings of time and temporalising practices coexist and interfere with one another in various degrees of tension or mutual indifference and with different distributions of agency (Brice 2014: 950; Greenhouse 1996). Different temporal regimes thus coexist and compete for influence - and as we know, 'time is also a question of power, the power to control movements, to decide about beginnings and endings, to set the pace, to give the rhythm' (Jordheim 2014: $510)$.

The temporal ecology covered in the Atlas does not include, however, the effects of Christian temporalities. Christianity was present in the region when Conklin conducted his fieldwork, although by far with as much impact as it has had in the latest three decades. Leaving what was of Christian influence out of the account was probably a deliberate choice by Conklin as he saw, as many of my informants did too, Christian influence, particularly Pentecostalism, as a potential threat towards the ecological sensibility of Ifugao agricultural practices (Conklin, personal communication $)^{8}$. Leaving the 'time politics' (Greenhouse 1996) of Protestant converts out of the account thus became part of Conklin's own 'time politics', of his attempt to show - to the public and the Philippine government - how Ifugao agricultural practices were ecologically sustainable and far from a traditional past that should be passed.

\footnotetext{
${ }^{8}$ I met Conklin in Bayninan, Banaue, in March 2004 when he was on one of his last fieldtrips to the area (see Remme 2017a).
} 
Ifugao agricultural practices have also seen other interruptions of the multispecies rhythms described in the Atlas. As shown by Acabado and Martin (2015), the Philippine government's introduction of new high-yielding varieties of rice during the 1970s Green Revolution wreaked havoc on traditional agricultural practices. Intended to boost the national production of rice, these new rice varieties had other growth patterns that interfered with the agricultural rhythms of local varieties. In addition, their susceptibility to pests and lack of resistance to local bacterial diseases led to extensive use of chemical pesticides. Killing fish, snails and other animals inhabiting the pond fields, these pesticides caused serious damage to the multispecies sympoeisis required for their maintenance. Such disruptive processes were then further exacerbated when the Department of Agriculture introduced the golden apple snail (Pomacea canaliculata) as a potential new protein source for the farmers. Gorging up rice plants and what fish and snails remained, the apple snails have turned many Ifugao rice fields into evidences of development projects clearly out of synch with what otherwise were quite robust and sustainable agricultural practices.

\section{Conclusion}

The detrimental effects of these later developments should alert us to the fact that a multispecies perspective is far from a matter of pure theoretical interest. It not only matters what terms we think Ifugao terraces with. It also matters through which terms they are done. Conklin surely understood this, and with his Atlas he left us a unique testimony of that which deserves far more appreciation than it has so far enjoyed.

Although often hailed as a radically new approach, attention to multispecies entanglements has in fact a history longer than the current branding oriented profusion of 'turns' in anthropology perhaps will admit. It would serve anthropology 
well, I hope this and the other articles in this special issue show, to look carefully for the affordances (Gibson 1979) that previous work on humans and nonhuman possibly contain. Perhaps they were closer to current ways of thinking than we suspected. Perhaps the political and theoretical landscape they operated in necessitated other ways of evidencing (see Engelke 2008) their claims, other ways than today's political climate, in both senses of the term, requires. And perhaps the continuity thus revealed could actually enhance the impact of multispecies ethnography.

We seem to live in a world in which the entanglements of humans and nonhumans become increasingly evident and take new and often unpredictable forms. Conklin's insistence on detailed documentation of the particular ways in which such entanglements unfold invites us to pay attention to specificities and the heterogeneous character of terms such as climate change and the Anthropocene which often comes readily homogenised (Bubandt and Tsing 2018).

Conklin was not among those anthropologists who churn out one book after the other. After the publication of the Atlas in 1980 and until he passed away in 2016, Conklin did not produce any other book length publications. Despite other anthropologists' favourable reviews and the deep respect Conklin enjoyed in the anthropological community, the Atlas had a quite limited impact on anthropological method, writing or theorising ${ }^{9}$. Perhaps some of the reason for this is that its dry and seemingly objective descriptions of human-nonhuman relations did not sit particularly

\footnotetext{
${ }^{9}$ It seems Conklin actually made more impact on anthropology through his Hanunóo research. His $\mathrm{PhD}$ thesis 'The relation of Hanunóo culture to the plant world' (1954b) is still considered a landmark in the development of ethnobiology (Hunn 2007; Dove 2017: 175; Ludwig 2018: 416).
} 
well with the theoretical perspectives and thematic interests - interpretation, meaning, emotions and personhood - that came to dominate mainstream anthropology at the time $^{10}$.

Conklin's influence weighted perhaps more heavily among his Ifugao friends. Deeply respected there too, his presence could be felt in far-away villages as well as in more central towns (Remme 2017a). Exhibited as a centrepiece of the local museum in Banaue, the Atlas has clearly been central to Ifugao ethno-political storytelling. That Conklin has contributed to Ifugao cultural self-confidence and resilience against government led development projects forces is beyond doubt. In that regard, one might ask if my 'dwelling' reading of the Atlas is not actually at odds with how Ifugao farmers see their own practices. But this is a matter that is far from one sided. On the one hand, the 'building' perspective that supports the promotion of the magnificent terraces as great engineering achievements has surely benefited the tourist industry in the area. On the other hand, many Ifugao farmers have currently initiated attempts at sustaining ways of farming more in accordance with a multispecies or ecological perspective that the 'dwelling reading' of the Atlas foregrounds.

In Greek mythology, Atlas was a Titan god who was condemned to carry the heavens on his shoulders and by that to hold cosmos together by preventing heaven and earth to resume their primordial collapse. Conklin's Atlas could be read as a

${ }^{10}$ Michelle Z. Rosaldo's examination of Ilongot notions of self and emotions in Knowledge and Passion (1980) for instance, was published the same year as the Atlas, as was Clifford Geertz's symbolic analysis in Negara: The Theatre State in Nineteenth Century-Bali (1980). 
rather conventional anthropocentric account of how Ifugao farmers through centuries have held their world together through their agricultural, social and cultural practices.

But as I have shown here, it does not take much to tweak that anthropocentric story into one that rather foregrounds the heterogeneous constellation of beings and forces involved in what is actually a dynamic and quite transformable 'worlding' (Tsing 2011). According to Greek myths, Atlas was the brother of Cronus, the god of time. That the Atlas is infused with temporality gives it a dimension that should alert us to the ways in which relations between humans, animals, plants and other nonhuman beings are both in time and about time. The recent periodisation of certain humanenvironmental entanglements called the Anthropocene testifies clearly to this connection, and perhaps it is about time now to look more carefully, more generously, at how these entanglements can be read, thought and enacted differently.

\section{References}

Acabado, Stephen. 2012. The Ifugao Agricultural Landscapes: Agro-Cultural Complexes and the Intensification Debate. Journal of Southeast Asian Studies, 43:500-522.

---. 2010. Landscapes and the Archaeology of Ifugao Agricultural Terraces: Establishing Antiquity and Social Organization. Hukay: Journal for Archaeological Research in Asia and the Pacific, 15:31-61.

Acabado, Steven, and Marlon Martin. 2015. Between Pragmatism and Cultural Context: Continuity and Change in Ifugao Wet-Rice Agriculture. In Water and Heritage: Material, Conceptual and Spiritual Connections, edited by Willem J. H. Willems and Henk P. J. van Schaik, 273-295. Leiden: Sidestone Press. Adam, Barbara. 1990. Time and Social Theory. Cambridge: Polity Press. Anderson, Myrdene. 2007. Comment: Ethnographic Analysis. In Fine Description: Ethnographic and Linguistic Essays, edited by Joel Kuipers and Ray McDermott, 59-62. New Haven: Yale Southeast Asian Studies.

Barad, Karen. 2007. Meeting the Universe Halfway: Quantum Physics and the Entanglement of Matter and Meaning. Durham: Duke University Press.

Barton, Roy Franklin. 1922. Ifugao Economics. American Archaeology and Ethnology, 15:385-446.

---. 1946. The Religion of the Ifugaos. American Anthropologist, 48:1-211.

---. 1969. Ifugao Law. Berkeley: University of California Press. Original edition, 1919, University of California Publications in American Archeology and Ethnology, Vol. 15, No. 1.

Beyer, Henry Otley. 1955. The Origin and History of the Philippine Rice Terracers. Proceedings, 8th Pacific Science Congress, I:380-398. 
Brice, Jeremy. 2014. Attending to Grape Vines: Perceptual Practices, Planty Agencies and Multiple Temporalities in Australian Viticulture. Social \& Cultural Geography, 15:942-965.

Bubandt, Nils, and Anna Tsing. 2018. An Ethnoecology for the Anthropocene: How a Former Brown-Coal Mine in Denmark Shows Us the Feral Dynamics of PostIndustrical Ruin. Journal of Ethnobiology, 38:1-13.

Cadena, Marisol de la. 2015. Earth Beings: Ecologies of Practice across Andean Worlds. Durham: Duke University Press.

Childe, Vere Gordon. 1928. The Most Ancient East: The Oriental Prelude to European Prehistory. London: Kegan Paul, Trench, Trubner \& Co.

Conklin, Harold C. 1954a. An Ethnoecological Approach to Shifting Agriculture. Transactions of The New York Academy of Sciences, 17:133-142.

---. 1954b. The Relation of Hanunóo Culture to the Plant World. PhD, Yale University.

---. 1980. Ethnographic Atlas of Ifugao: A Study of Environment, Culture, and Society in Northern Luzon. New Haven: Yale University Press.

Descola, Philippe. 2013. Beyond Nature and Culture. Chicago: The University of Chicago Press.

Despret, Vinciane. 2008. The Becomings of Subjectivity in Animal Worlds. Subjectivity, 23.

Dove, Michael R. 1983. Ethnographic Atlas of Ifugao: Implications for Theories of Agricultural Evolution in Southeast Asia Current Anthropology, 24:516-519.

---. 2007. Kinds of Fields. In Fine Description: Ethnographic and Linguistic Essays, edited by Joel Kuipers and Ray McDermott, 411-427. New Haven: Yale Southeast Asia Studies.

---. 2017. Harold C. Conklin (1926-2016). American Anthropologist, 119:174-182.

Engelke, Matthew. 2008. The Objects of Evidence. The Journal of the Royal Anthropological Institute, 14:1-21.

Evans-Pritchard, Edward E. 1969. The Nuer: A Description of the Modes of Livelihood and Political Institutions of a Nilotic People. Oxford: Oxford University Press.

Frake, Charles O. 1962. Cultural Ecology. American Anthropologist, 64:53-59.

---. 2007. Fine Description. In Fine Description: Ethnographic and Linguistic Essays, edited by Joel Kuipers and Ray McDermott, ix-xvii. New Haven: Yale University Southeast Asian Studies.

Gan, Elaine. 2016. Time Machines: Making and Unmaking Rice. PhD thesis, University of California Santa Cruz.

Geertz, Clifford. 1973. The Interpretations of Cultures. Selected Essays. London: Fontana Press.

---. 1980. Negara. Princeton: Princeton University Press.

---. 2007. On Paying Attention. In Fine Description: Ethnographic and Linguistic Essays by Harold C. Conklin, edited by Joel Kuipers and Ray McDermott, 2729. New Haven: Yale Southeast Asia Studies.

Gibson, James J. 1979. The Ecological Approach to Visual Perception. Boston: Houghton Mifflin Harcourt.

Greenhouse, Carol. 1996. A Moment's Notice: Time Politics across Cultures. Ithaca, NY: Cornell University Press.

Hanks, Lucien M. 1982. Review of Ethnographic Atlas of Ifugao: A Study of Environment, Culture and Society in Northern Luzon. American Ethnologist, 9:206-208. 
Haraway, Donna. 2008. When Species Meet. Minnesota: University of Minnesota Press.

---. 2016. Staying with the Trouble: Making Kin in the Chthulucene. Durham: Duke University Press.

Harris, Mark. 1998. The Rhythm of Life on the Amazon Floodplain: Seasonality and Sociality in a Riverine Village. Journal of the Royal Anthropological Institute, 4:65-82.

Hunn, Eugene S. 2007. Conklin's Ethnobiological Contribution. In Fine Description: Ethnographic and Linguistic Essays by Harold C. Conklin, edited by Joel Kuipers and Ray McDermott, 191-195. New Haven: Yale University Southeast Asian Studies

Ingold, Tim. 2000. The Perception of the Environment: Essays on Livelihood, Dwelling and Skill. London: Routledge.

Jordheim, Helge. 2014. Introduction: Multiple Times and the Work of Synchronization. History and Theory, 53:498-518.

Keane, Webb. 2007. Christian Moderns: Freedom and Fetish in the Mission Encounter. Edited by Joel Robbins, The Anthropology of Christianity. Berkeley: University of California Press.

Keesing, Felix M. 1962. The Ethnohistory of Northern Luzon. Stanford: Stanford University Press.

Kirksey, Eben, ed. 2014. The Multispecies Salon. Durham and London: Duke University Press.

Kirksey, Eben, Craig Schuetze, and Stefan Helmreich. 2014. Tactics of Multispecies Ethnography. In The Multispecies Salon, edited by Eben Kirksey, 1-24. Durham: Duke University Press.

Kirksey, S. Eben, and Stefan Helmreich. 2010. The Emergence of Multispecies Ethnography. Cultural Anthropology, 25:545-576.

Kohn, Eduardo. 2013. How Forests Think: Toward an Anthropology Beyond the Human. Berkeley: University of California Press.

Krause, Franz. 2013. Seasons and Rhythms on the Kemi River in Finnish Lapland. Ethnos: Journal of Anthropology, 78:23-46.

Kuipers, Joel, and Ray McDermott. 2007. Ethnographic Responsibility. In Fine Description: Ethnographic and Linguistic Essays by Harold C. Conklin, edited by Joel Kuipers and Ray McDermott, 1-24. New Haven: Yale Southeast Asia Studies.

Lambrecht, Francis. 1932-1951. The Mayawyaw Ritual. Publication of the Catholic Anthropological Conference, 4:1-754.

Levi-Strauss, Claude. 1969. The Raw and the Cooked: Mythologiques, Volume 1. Chicago: The University of Chicago Press.

Lien, Marianne E. 2015. Becoming Salmon: Aquaculture and the Domestication of a Fish. Berkeley: University of California Press.

Lien, Marianne E., Gro B. Ween, and Heather A. Swanson. 2018. Naming the Beast: Exploring the Otherwise. In Domestication Gone Wild: Politics and Practices of Multispecies Relations, edited by Heather A. Swanson, Marianne E. Lien and Gro B. Ween, 4-42. Durham: Duke University Press.

Ludwig, David. 2018. Revamping the Metaphysics of Ethnobiological Classification. Current Anthropology, 59:415-438.

Malinowski, Bronislaw. 1935. Coral Gardens and Their Magic: A Study of the Methods of Tilling the Soil and of Agricultural Rites in the Trobriand Islands. Vol. 1. London: Allen \& Unwin. 
Masipiqueña, Andres, Gerard A. Persoon, and Denyse J. Snelder. 2000. The Use of Fire in Northern Luzon (Philippines): Conflicting Views of Local People, Scientists and Government Officials. In Indigenous Environmental Knowledge and Its Transformations. Critical Anthropological Perspectives, edited by Roy Ellen, Peter Parkes and Alan Bicker, 177-212. Amsterdam: Harwood Academic Publishers.

Mintz, Sidney W. 1986. Sweetness and Power: The Place of Sugar in Modern History. New York: Penguin Books.

Remme, Jon Henrik Ziegler. 2014a. A Dispositional Account of Causality: From Herbal Insecticides to Theories of Emergence and Becoming. Anthropological Theory, 14:405-421.

---. 2014b. Pigs and Persons in the Philippines: Human-Animal Entanglements in Ifugao Rituals. Lanham: Lexington Books.

---. 2016. Actualizing Spirits: Ifugao Animism as onto-Praxis. In Animism in Southeast Asia, edited by Kaj Århem and Guido Sprenger, 138-153. New York: Routledge.

---. 2017a. Ethnographies Returned: The Mobilisation of Ethnographies and the Politicisation of Indigeneity in Ifugao, the Philippines. In Handbook of Indigenous Religion(S), edited by Greg Johnson and Siv Ellen Kraft, 294-308. Boston: Brill.

---. 2017b. Human at Risk: Becoming Human and the Dynamics of Extended Sociality. In Human Nature and Social Life: Perspectives on Extended Sociality, edited by Jon Henrik Ziegler Remme and Kenneth Sillander, 54-67. Cambridge: Cambridge University Press.

---. 2018. Pigs and Spirits in Ifugao: A Cosmological Decentering of Domestication. In Domestication Gone Wild: Politics and Practices of Multispecies Relations, edited by Heather A. Swanson, Marianne E. Lien and Gro B. Ween. Durham: Duke University Press.

Rosaldo, Michelle Z. 1980. Knowledge and Passion: Ilongot Notions of Self and Social Life. Cambridge: Cambridge University Press.

Rosaldo, Renato. 1993. Culture and Truth: The Remaking of Social Analysis. London: Routledge.

Sahlins, Marshall. 2017. The Original Political Society. HAU: Journal of Ethnographic Theory, 7:91-128.

Smith, Jonathan Z. 1972. I Am a Parrott (Red). History of Religions, 11:391-413.

Sturtevant, Willam C. 1964. Studies in Ethnoscience. American Anthropologist, 66:99-131.

Swanson, Heather A.. 2018. Domestication Gone Wild: Disrupting the Domus. In Domestication Gone Wild: Politics and Practices of Multispecies Relations, edited by Marianne Elisabeth Lien, Heather Anne Swanson and Gro B. Ween, 184-211. Durham: Duke University Press.

Tsing, Anna. 2011. Worlding the Matsutake Diaspora: Or, Can Actor-Network Theory Experiment with Holism? In Experiments in Holism: Theory and Practice in Contemporary Anthropolopgy, edited by Ton Otto and Nils Bubandt, 47-66. Oxford: Wiley-Blackwell.

---. 2012. Unruly Edges: Mushrooms as Companion Species: For Donna Haraway. Environmental Humanities, 1:141-154.

---. 2013. More-Than-Human-Sociality: A Call for Critical Description. In Anthropology and Nature, edited by Kirsten Hastrup, 27-42. New York: Routledge. 
---. 2015. The Mushroom at the End of the World: On the Possibility of Life in Capitalist Ruins. Princeton: Princeton University Press.

Viveiros de Castro, Eduardo. 2007. The Crystal Forest: Notes on the Ontology of Amazonian Spirits. Inner Asia, 9:153-172.

Willcox, Cornélis de Witt. 1912. The Head Hunters of Northern Luzon. Kansas City: Franklin Hudson Publishing. 